\title{
Lysophosphatidic acid inhibition of the accumulation of Pseudomonas aeruginosa PA01 alginate, pyoverdin, elastase and LasA
}

\author{
David C. Laux, ${ }^{1}$ Joy M. Corson, ${ }^{1}$ Michael Givskov, ${ }^{2}$ Morten Hentzer, ${ }^{2}$ \\ Annette Møller, ${ }^{1}$ Kathleen A. Wosencroft, ${ }^{1}$ Joan C. Olson, ${ }^{3}$ \\ Karen A. Krogfelt, ${ }^{4}$ Joanna B. Goldberg ${ }^{5}$ and Paul S. Cohen ${ }^{1}$
}

Author for correspondence: Paul S. Cohen. Tel: +1 401874 5920. Fax: +1 4018742202. e-mail: pco1697u@postoffice.uri.edu

\footnotetext{
1 Department of Cell and Molecular Biology, University of Rhode Island, Kingston, RI 02881, USA

2 Biocentrum, Bldg 301, Technical University of Denmark, DK-2800 Lyngby, Denmark

3 Department of Pathology and Laboratory Medicine, Medical University of South Carolina, Charleston, SC 29425, USA

4 Department of Gastrointestinal Infections, Statens Serum Institut, DK 2300 Copenhagen, Denmark

5 Department of Microbiology, University of Virginia, Health Sciences Center, Charlottesville, VA 22908, USA
}

\begin{abstract}
The pathogenesis of Pseudomonas aeruginosa is at least partially attributable to its ability to synthesize and secrete the siderophore pyoverdin and the two zinc metalloproteases elastase and LasA, and its ability to form biofilms in which bacterial cells are embedded in an alginate matrix. In the present study, a lysophospholipid, 1-palmitoyl-2-hydroxy-sn-glycero-3-phosphate [also called monopalmitoylphosphatidic acid (MPPA)], which accumulates in inflammatory exudates, was shown to inhibit the extracellular accumulation of $P$. aeruginosa PAO1 alginate, elastase, LasA protease and the siderophore pyoverdin. MPPA also inhibited biofilm formation. The inhibitory effects of MPPA occur independently of rpos expression and without affecting the accumulation of the autoinducers $\mathbf{N}$-(3-oxododecanoyl) homoserine lactone and $\boldsymbol{N}$-butyryl-Lhomoserine lactone, and may be due, at least in part, to the ability of MPPA to bind divalent cations.
\end{abstract}

Keywords: monopalmitoylphosphatidic acid, cystic fibrosis

\section{INTRODUCTION}

Pseudomonas aeruginosa is an opportunistic pathogen that rarely causes pulmonary disease in healthy hosts, but which causes acute pneumonia in immunocompromised patients (Bodey et al., 1983). It is also associated with chronic pneumonia in cystic fibrosis patients (Bodey et al., 1983; Ojeniji, 1994). P. aeruginosa produces several virulence factors that contribute to its pathogenesis, including lipopolysaccharide (LPS) (Cryz et al., 1984; Tang et al., 1996), the two ADP-ribosylating enzymes exotoxin A (Vasil et al., 1993) and exoenzyme S (Nicas et al., 1985), the exoproteases elastase (Woods et al., 1982), LasA (Preston et al., 1997) and alkaline protease (Howe \& Iglewski, 1984), a haemolytic and a non-haemolytic phospholipase C (Vasil et al., 1993), the siderophores pyochelin and pyoverdin (Cox, 1993), the

Abbreviations: $\mathrm{BHL}, \mathrm{N}$-butanoyl homoserine lactone; GFP, green fluorescent protein; LB, Luria broth; LPS, lipopolysaccharide; MPPA, 1-palmitoyl2-hydroxy-sn-glycero-3-phosphate (also known as monopalmitoylphosphatidic acid); OdDHL, $\mathrm{N}$-(3-oxododecanoyl) homoserine lactone. surface-associated polysaccharide alginate (Baltimore, 1993), and pilus-associated adhesins responsible for binding to specific epithelial-cell receptors (Tang et al., 1995).

The expression of elastase, as well as the expression of a large number of other virulence factors, by $P$. aeruginosa is regulated by quorum sensing (Van Delden \& Iglewski, 1998). In P. aeruginosa there are at least two different quorum-sensing systems, las (Gambello \& Iglewski, 1991) and $r h l$ (Ochsner \& Reiser, 1995), which consist of two signal-generating synthetases (LasI/RhlI) and two cognate transcriptional regulators (LasR/ RhIR). The major products of the peptides LasI and RhlI are the autoinducers $\mathrm{N}$-(3-oxododecanoyl) homoserine lactone (OdDHL; also referred to as $3 \mathrm{OC}_{12}$-HSL or PAI1) (Pearson et al., 1994) and N-butanoyl homoserine lactone (BHL; also referred to as $\mathrm{C}_{4}$-HSL or PAI-2) (Pearson et al., 1995; Winson et al., 1995), respectively. These two quorum-sensing systems have been shown to be involved in biofilm differentiation (Davies et al., 1998). Biofilm differentiation plays an important role in 
the protection of $P$. aeruginosa from the host-defence system and from the action of antibiotics (Costerton et al., 1987). In addition, OdDHL interferes with the host immune system, where it specifically down-regulates the production of the cytokines IL-12 and TNF- $\alpha$ which support the bactericidal Th-1 milieu and protect the host, a finding which has to led the suggestion that the signal molecule is also an important virulence factor (Telford et al., 1998).

In addition to being regulated by quorum-sensing systems, Pseudomonas spp. virulence factors are produced in response to a variety of environmental factors. For example, several of the extracellular virulence factors accumulate to maximal levels only under conditions of low iron in the growth medium, e.g. the siderophores pyochelin and pyoverdin, exotoxin A, and the exoproteases elastase and alkaline protease (Cox, 1993; Vasil \& Ochsner, 1999). In addition, zinc has been shown to enhance pyoverdin production (Höfte et al., 1993; Rossbach et al., 2000), and zinc and calcium have been shown to be important for the efficient production and processing of elastase and the LasA protease (Brumlik \& Storey, 1992; Olson \& Ohman, 1992). Evidence also exists suggesting that limiting phosphate availability may also be an environmental signal in inducing phospholipase C synthesis (Shortridge et al., 1992).

In the present study, evidence is presented which indicates that a specific lysophospholipid, 1-palmitoyl2-hydroxy-sn-glycero-3-phosphate [also called monopalmitoylphosphatidic acid (MPPA)], which is generated by the secretory phospholipase A2 and accumulates in inflammatory exudates (Fourcade et al., 1998; Paya et al., 1996), inhibits the extracellular accumulation of alginate, pyoverdin, elastase and LasA protease in cultures of $P$. aeruginosa PAO1 grown in Luria broth (LB).

\section{METHODS}

Bacterial strains and plasmids. The bacterial strains and plasmids used in this study are listed in Table 1.

Preparation of LB containing MPPA. MPPA was purchased from Avanti Polar-Lipids. It was added to LB (EZ Mix Powder; Sigma) at a concentration of $500 \mu \mathrm{g} \mathrm{ml}^{-1}$. The mixture was sonicated for $5 \mathrm{~min}$ in an ultrasonic water bath at room temperature, and then incubated overnight at $37^{\circ} \mathrm{C}$ in a circulating water bath. After this incubation, undissolved MPPA was removed by centrifugation at $16000 \mathrm{~g}$ for $10 \mathrm{~min}$ at room temperature. The supernatant contains approximately $160 \mu \mathrm{M}$ MPPA (Krogfelt et al., 2000). LB containing $160 \mu \mathrm{M}$ MPPA was diluted $1: 1$ with LB, to give LB containing $80 \mu \mathrm{M}$ MPPA. The diluted LB was then diluted $1: 1$ with LB, to give LB containing $40 \mu \mathrm{M}$ MPPA.

Determination of the zinc and iron content of the LB and the LB containing MPPA. The zinc and iron contents of the LB and the LB containing MPPA $(80 \mu \mathrm{M})$ were determined by atomic absorption (CEIMIC). The zinc and iron concentrations in LB lot $98 \mathrm{H} 8213$ were $10 \cdot 3$ and $7 \cdot 2 \mu \mathrm{M}$, respectively, and in lot $109 \mathrm{H} 8206$ they were 10.6 and $7 \cdot 2 \mu \mathrm{M}$, respectively. In the LB (lot 98H8213) containing $80 \mu \mathrm{M} \mathrm{MPPA}$, the zinc and iron concentrations were 5.7 and $3.6 \mu \mathrm{M}$, respectively.
Culture conditions and growth measurements. $P$. aeruginosa PAO1 was grown overnight in a rotary-shaking water bath at $37^{\circ} \mathrm{C}$ to about $10^{9}$ c.f.u. $\mathrm{ml}^{-1}$. The next day, $P$. aeruginosa PAO1 was inoculated at $10^{3}$ c.f.u. $\mathrm{ml}^{-1}$ into culture tubes $(15 \mathrm{~mm} \times 100 \mathrm{~mm})$ containing $2 \mathrm{ml}$ aliquots of $\mathrm{LB}$ or $2 \mathrm{ml}$ aliquots of LB containing MPPA. Cultures were incubated by standing them in a water bath at $37^{\circ} \mathrm{C}$ for periods of up to $48 \mathrm{~h}$, as required. Growth was assayed by optical density measurements at $500 \mathrm{~nm}$ and, where indicated, by viable counts. In all experiments in which green fluorescent protein (GFP) synthesis was measured, $P$. aeruginosa PAO1 containing the plasmid pMRP17R ${ }^{-}$, which expresses the GFP, was grown in the presence of carbenicillin $\left(60 \mu \mathrm{g} \mathrm{ml}^{-1}\right)$, which prevents loss of the plasmid.

Quantification of GFP in liquid cultures. Expression of las $B:: g f p$ was measured by detection of the green fluorescence with a Perkin Elmer LS-5B Luminescence Spectrometer (470 $\mathrm{nm}$ excitation wavelength; $515 \mathrm{~nm}$ emission wavelength). At the time of measurement, the background fluorescence emitted by un-inoculated LB was used as a control, and this value (routinely about 50) was subtracted from the subsequent sample values. Cultures were diluted fivefold in LB; the fluorescence emitted by these diluted cultures of $P$. aeruginosa PAO1(pMRP17R ${ }^{-}$) was routinely about 250 . The background fluorescence measured in fivefold-diluted LB-grown cultures of $P$. aeruginosa PAO1 without $\mathrm{pMRP} 17 \mathrm{R}^{-}$was routinely about 50. In each experiment, fluorescence measurements of a fivefold-diluted $48 \mathrm{~h} \mathrm{LB}$-grown culture of $P$. aeruginosa PAO1(pMRP17R ${ }^{-}$) diluted additionally over a 20 -fold range generated a linear standard curve. This curve was used to calculate the relative amounts of fluorescence in each of the remaining cultures within that experiment.

Assays for pyoverdin and proteolytic activity in culture supernatants. Culture supernatants for assays of proteolytic activity and the presence of pyoverdin were prepared by centrifugation (16000 $\mathrm{g}$ for $10 \mathrm{~min}$ at room temperature). The relative amounts of pyoverdin present in culture supernatants were measured at $A_{380}$ (Haas et al., 1991). The proteolytic activity of the culture supernatants was measured on nutrient broth casein agar plates [Nutrient agar (Difco) plus 1\% skim milk powder] containing $100 \mu \mathrm{g}$ streptomycin sulfate $\mathrm{ml}^{-1}$ (to prevent growth of residual bacteria). Supernatant samples $(50 \mu \mathrm{l})$ were added to wells within the plates, which had been made by removing agar plugs $(6.5 \mathrm{~mm}$ diameter $)$. The plates were incubated for $24 \mathrm{~h}$ at $37^{\circ} \mathrm{C}$, after which time the diameter of the zone of casein hydrolysis was measured. To compare the relative amounts of proteolytic activity within the culture supernatants (on the basis of $50 \mu \mathrm{l}$ aliquots) from each experiment, a standard curve of proteolytic activity was generated. This was done by diluting a fresh LB-grown culture supernatant with LB such that the diameters $(\mathrm{mm})$ of the zones of casein hydrolysis obtained from $50 \mu$ l aliquots of the diluted LB-grown culture related to proteolytic activities of 100, 80, $60,40,20,10,5$ and $2 \cdot 5 \%$. Standard curves for the actual proteolytic activities $(\mathrm{mm})$ versus the $\log _{10}$ of the theoretical activities ( $\%)$ were linear.

Immunoblot analysis of LasB and LasA. Washed pellets from $2 \mathrm{ml}$ cultures of $P$. aeruginosa PAO1 were resuspended in $2 \mathrm{ml}$ of fresh LB and sonicated as described previously (Zhou et al., 1997). Sonicates $(500 \mu \mathrm{l})$ and cell-free filtered $(0 \cdot 22 \mu \mathrm{m}$ pore size) supernatants $(500 \mu \mathrm{l})$ were mixed with $100 \mu \mathrm{l}$ of $6 \times$ concentrated sample buffer $(0.35 \mathrm{M}$ Tris/ $\mathrm{HCl}, \mathrm{pH} 6 \cdot 8 ; 10 \%$ SDS; $6 \%$ 2-mercaptoethanol; 30\% (v/v) glycerol; $0 \cdot 012 \%$ bromophenol blue). The mixtures were boiled for $5 \mathrm{~min}$ and 
MPPA and $P$. aeruginosa PAO1 virulence factors

Table 1. Bacterial strains and plasmids used in this study

\begin{tabular}{|c|c|c|}
\hline Bacteria/plasmid & Relevant genotype/phenotype & Source/reference \\
\hline \multicolumn{3}{|l|}{ P. aeruginosa } \\
\hline PAO1 & Wild-type & Toder et al. (1994) \\
\hline PAO-B1 & las $B:: \Omega$ of PAO1 & Toder et al. (1994) \\
\hline PAO-MW20 & rpoS mutant of PAO1; $\mathrm{Gm}^{\mathrm{R}}$ & Whitely et al. (2000) \\
\hline \multicolumn{3}{|l|}{ Plasmids } \\
\hline pMH297 & OdDHL monitor, lasB: :luxCDABE $\mathrm{P}_{l a c}::$ lasR; $\mathrm{Ap}^{\mathrm{R}}$ & Charlton et al. (2000) \\
\hline pSB536 & BHL monitor, ahyR abyI::luxCDABE; $\mathrm{Ap}^{\mathrm{R}}$ & Swift et al. (1997) \\
\hline pMRP17R ${ }^{-}$ & $\begin{array}{l}\text { lasB::gfp transcriptional fusion, contains the las } B \text { promoter, its } \\
\text { upstream transcriptional regulatory region, and } g f p \text { in } p E X 1.8 \\
\text { (Pearson et al., 1997); } \mathrm{Ap}^{\mathrm{R}}\end{array}$ & M. R. Parsek \\
\hline
\end{tabular}

samples $(40 \mu \mathrm{l})$ were loaded alongside pre-stained protein standards (BioRad). Samples were separated on $10 \%$ acrylamide gels and were transferred to nitrocellulose membranes by standard methods (Gallagher, 1999; Gallagher et al., 1997). Blots were treated with 1:8000 dilutions of either rabbit antielastase serum (Olson \& Ohman, 1992) or rat anti-LasA serum (Olson \& Ohman, 1992). The chemiluminescent detection of LasB or LasA was performed using the appropriate secondary antibody and the protocol supplied with the ECL chemiluminescence Western-blotting kit (Amersham Pharmacia Biotech). Relative amounts of the $33 \mathrm{kDa}$ elastase protein made in the presence and absence of MPPA were determined by densitometry (Molecular Dynamics Personal Densitometer SI)

Extraction of autoinducers. Autoinducers were isolated from $2 \mathrm{ml}$ static cultures of $P$. aeruginosa PAO1 grown at $37^{\circ} \mathrm{C}$. The cultures were homogenized by vortexing, and the cells were pelleted by centrifugation. Cell-free supernatants were extracted twice in glass test tubes with $3 \mathrm{ml}$ acidified ethyl acetate $(100 \mu \mathrm{l}$ glacial acid per $100 \mathrm{ml})$. The solvent was removed by evaporation under a gentle stream of nitrogen gas. The dried residues were re-dissolved in $100 \mu \mathrm{l}$ of ethanol and stored at $-20^{\circ} \mathrm{C}$.

Assay of autoinducer concentration. The concentrations of the autoinducers in the extracted cultures were determined by a bioluminescent assay. OdDHL and BHL activities were assayed by use of E. coli JM109-based monitor strains harbouring pMH297 and pSB536, respectively (Table 1). Overnight cultures of the autoinducer monitor strains were subcultured at an $\mathrm{OD}_{450}$ of 0.05 in $\mathrm{AB}$ minimal medium (Clark \& Maaløe, 1967) supplemented with $0 \cdot 1 \%$ glucose and Casamino acids. The cultures were grown with shaking $(200$ r.p.m.) at $37^{\circ} \mathrm{C}$. At $\mathrm{OD}_{450} 0 \cdot 3$, the cultures were split into aliquots and each aliquot was placed in a $5 \mathrm{ml}$ glass test tube. Autoinducer extracts were added $(2 \mu \mathrm{l}$ per $1.0 \mathrm{ml}$ culture $)$, and the cultures were further incubated for $2 \mathrm{~h}$ at $37^{\circ} \mathrm{C}$ with shaking (200 r.p.m.). A $100 \mu \mathrm{l}$ sample of each culture was retrieved for measurement of its bioluminescence (1253 Luminometer, Bio-Orbit Oy, Turku, Finland) and its $\mathrm{OD}_{450}$ value. The autoinducer activity was calculated as the specific bioluminescence. The autoinducer concentration in the extracted cultures was determined from a standard curve generated by use of pure autoinducer standards.

Biofilm formation. This was assessed using the procedure of O'Toole et al. (1999). Twenty-four-well Nunclon polystyrene culture plates (Nunc, Roskilde, Denmark) containing $2 \mathrm{ml} \mathrm{LB}$ or $2 \mathrm{ml}$ LB containing $80 \mu \mathrm{M}$ MPPA were inoculated, as described above. Following 28 or $48 \mathrm{~h}$ of incubation at $37^{\circ} \mathrm{C}$, the wells were washed four times with LB and stained with crystal violet. After washing to remove excess stain, the remaining crystal violet dye was solubilized with $2.5 \mathrm{ml}$ of $95 \%$ ethyl alcohol. The solubilized dye was then diluted twofold and the level of crystal violet recovered was assessed in a spectrophotometer at $580 \mathrm{~nm}$.

Alginate determination. Ten static $2 \mathrm{ml} \mathrm{LB}$-grown cultures of $P$. aeruginosa $\mathrm{PAO} 1$ (incubated for $48 \mathrm{~h}$ at $37^{\circ} \mathrm{C}$ ) were pooled and added to $60 \mathrm{ml}$ of $0.9 \%$ sterile saline. The mixture was vortexed extensively and centrifuged at $10000 \mathrm{~g}$ for $12 \mathrm{~min}$ at room temperature. The supernatant was saved and the pellet was resuspended in $5 \mathrm{ml}$ of $0.9 \%$ sterile saline, vortexed extensively and then centrifuged as above. The first and second supernatants were combined, ethanol precipitated and then assayed for alginate, as described by May \& Chakrabarty (1994). The pellet was assayed for protein (see below) using the Lowry method. Ten static $2 \mathrm{ml} P$. aeruginosa PAO1 cultures grown in LB containing MPPA $(80 \mu \mathrm{M})$ were assayed for the presence of alginate and protein in the same manner as the LB-grown cultures.

Protein determinations. Statically grown $2 \mathrm{ml}$ cultures of $P$. aeruginosa PAO1 were centrifuged at room temperature for $10 \mathrm{~min}$ at $10000 \mathrm{~g}$. The cell pellets were resuspended in $1 \mathrm{ml}$ of saline and were precipitated with $1 \mathrm{ml}$ of $10 \%(\mathrm{w} / \mathrm{v})$ trichloroacetic acid (TCA). The precipitates were centrifuged at room temperature for $10 \mathrm{~min}$ at $10000 \mathrm{~g}$, and were resuspended in $100 \mu \mathrm{l}$ of $1 \mathrm{M} \mathrm{NaOH}$. Supernatants from the static cultures were filtered free of $P$. aeruginosa PAO1 $(0 \cdot 22 \mu \mathrm{m}$ pore-size filters $)$, TCA-precipitated and then resuspended in $1 \mathrm{M} \mathrm{NaOH}$, as described above. Protein determinations of the cell and supernatant fractions were performed using the Lowry method.

Isolation of LPS and immunological detection. O-serotyping was performed at the Statens Seruminstitut, as described by Liu et al. (1983). LPS was isolated from $48 \mathrm{~h}$ static cultures of $P$. aeruginosa PAO1, as described previously (Coyne et al., 1994). LPS samples were analysed for O5 antigen by immunoblotting SDS polyacrylamide gels, as described previously (Coyne et al., 1994).

Statistics. Student's $t$-test was used to evaluate the effect of MPPA on $P$. aeruginosa PAO1 growth, pyoverdin accumulation and exoprotease synthesis. 


\section{RESULTS}

Growth, presence of pyoverdin, and exoprotease production in shake and static cultures of $P$. aeruginosa PAO1

In a preliminary set of experiments, bacterial growth, the presence of pyoverdin and exoprotease production were compared after 24 and $48 \mathrm{~h}$ incubation at $37^{\circ} \mathrm{C}$ in shake $(20 \mathrm{ml})$ and static $(2 \mathrm{ml})$ LB-grown cultures inoculated with $P$. aeruginosa PAO1 at $10^{3}$ c.f.u. $\mathrm{ml}^{-1}$. Whereas growth in the shake cultures $\left(\mathrm{OD}_{500}\right)$ was about twice that of the static cultures, pyoverdin production in the shake cultures was only half that observed in the static cultures. Cell-free supernatants of the shake cultures exhibited no exoprotease activity on casein agar plates, whereas cell-free supernatants of the static cultures could be diluted 20- to 30-fold and still exhibited exoprotease activity (data not shown). In addition, LB-grown static cultures of $P$. aeruginosa PAO1 allowed the formation of a distinct biofilm. For these reasons, we used static LB-grown cultures for the studies detailed below.

\section{Effect of MPPA on the growth of $P$. aeruginosa PAO1 and on the extracellular accumulation of pyoverdin and exoprotease}

Specific phospholipids enhance the activity of $\beta$-lactam antibiotics against LB-grown $P$. aeruginosa $\mathrm{PAO} 1$ and against LB-grown $P$. aeruginosa strains isolated from the sputum of cystic fibrosis patients (Krogfelt et al., 2000). The most active phospholipid is MPPA (Krogfelt et al., 2000). Experiments were performed to determine whether MPPA has any effect on P. aeruginosa PAO1 growth and on pyoverdin and exoprotease production. LB-grown cultures of $P$. aeruginosa PAO1 $(2 \mathrm{ml})$, inoculated at about $10^{3}$ c.f.u. $\mathrm{ml}^{-1}$, were grown statically at $37^{\circ} \mathrm{C}$ for $48 \mathrm{~h}$ in the presence of 40 and $80 \mu \mathrm{M}$ MPPA. The presence of $40 \mu \mathrm{M}$ MPPA in the growth medium had no effect on $P$. aeruginosa $\mathrm{PAO} 1$ growth nor on the accumulation of extracellular pyoverdin; however, extracellular exoprotease activity was reduced by about 10 -fold $(P<0.05)$ (Table 2$)$. In the presence of $80 \mu \mathrm{M}$ MPPA, the $P$. aeruginosa PAO1 doubling time was increased by about 1.5 -fold $(3.62 \mathrm{~h}$ when grown in LB alone compared to $5.33 \mathrm{~h}$ when grown in $\mathrm{LB}+\mathrm{MPPA}$ ) (Fig. 1), the final growth yield (measured at $\mathrm{OD}_{500}$ ) was reduced by $40 \%(P<0 \cdot 001)$, the extracellular accumulation of pyoverdin was reduced by $67 \%(P<0.001)$, and extracellular protease activity was undetectable (Table 2). In control experiments, MPPA $(80 \mu \mathrm{M})$ was added to the cell-free supernatants containing exoprotease activity and the mixture was incubated at $37^{\circ} \mathrm{C}$ for $24 \mathrm{~h}$. Under these conditions, MPPA had no effect on exoprotease activity, ruling out the possibility that the exoproteases were inactivated by MPPA.

$P$. aeruginosa PAO1 is known to secrete at least two exoproteases, elastase (encoded by lasB) and LasA (encoded by las $A$ ). To determine which exoprotease was detected by the casein agar plate assay, the following experiment was performed. $P$. aeruginosa PAO-B1, a las B mutant of our PAO1 strain (Toder et al., 1994), was grown statically in $2 \mathrm{ml} \mathrm{LB}$ cultures for $48 \mathrm{~h}$ at $37^{\circ} \mathrm{C}$. The culture supernatant was then assayed for proteolytic activity in the wells of casein agar plates, as described in Methods. P. aeruginosa PAO-B1 cell-free supernatants did not shown any protease activity when placed in wells in casein agar plates, although this strain is known to synthesize LasA (Toder et al., 1994). In contrast, $P$. aeruginosa PAO1 cell-free supernatants could be diluted greater than 20 -fold and still showed proteolytic activity. These data suggest that the only exoprotease being detected on casein plates with wells containing the $P$. aeruginosa $\mathrm{PAO} 1$ cell-free culture supernatants, derived from $2 \mathrm{ml}$ statically grown cultures, was elastase. Hence, the exoprotease activity on casein agar plates will be referred to as elastase activity from this point on. However, it should be noted that although it appears elastase is the only protease detected on casein agar plates, we do not mean to imply that elastase is the only protease synthesized in static LB-grown cultures of $P$. aeruginosa PAO1. In fact, as described below, although not detected on casein agar plates, $P$. aeruginosa $\mathrm{PAO} 1$ produces LasA protease in static LB cultures.

\section{lasB::gfp expression in the presence of MPPA}

To investigate the effect of MPPA on the transcription of las $B$, a las $B:: g f p$ transcriptional fusion, containing the regulatory region upstream of lasB (Rust et al., 1996; Dr

Table 2. Effect of MPPA on $P$. aeruginosa PAO1 growth, pyoverdin production and exoprotease accumulation

Cultures were grown statically for $48 \mathrm{~h}$ at $37^{\circ} \mathrm{C}$.

\begin{tabular}{|lccc|}
\hline Growth medium & Growth $\left(\mathrm{OD}_{500}\right)$ & Pyoverdin $\left(\boldsymbol{A}_{380}\right)$ & Exoprotease $(\%)$ \\
\hline LB $(n=15)$ & $1 \cdot 53 \pm 0 \cdot 09$ & $1 \cdot 69 \pm 0 \cdot 18$ & $100 \pm 2 \cdot 60^{*}$ \\
LB + MPPA $(40 \mu \mathrm{M} ; n=6)$ & $1 \cdot 69 \pm 0 \cdot 40$ & $1 \cdot 41 \pm 0 \cdot 42$ & $9 \cdot 10 \pm 6 \cdot 00$ \\
LB + MPPA $(80 \mu \mathrm{M} ; n=15)$ & $0 \cdot 92 \pm 0 \cdot 12$ & $0 \cdot 56 \pm 0 \cdot 20$ & 0 \\
\hline
\end{tabular}

* One hundred percent exoprotease activity corresponds to a $20.0 \mathrm{~mm}$ in diameter zone of casein hydrolysis (including the $6.5 \mathrm{~mm}$ diameter of the well). The exoprotease activity in cultures grown in the presence of $40 \mu \mathrm{M}$ MPPA was determined using a standard curve, as described in Methods. 

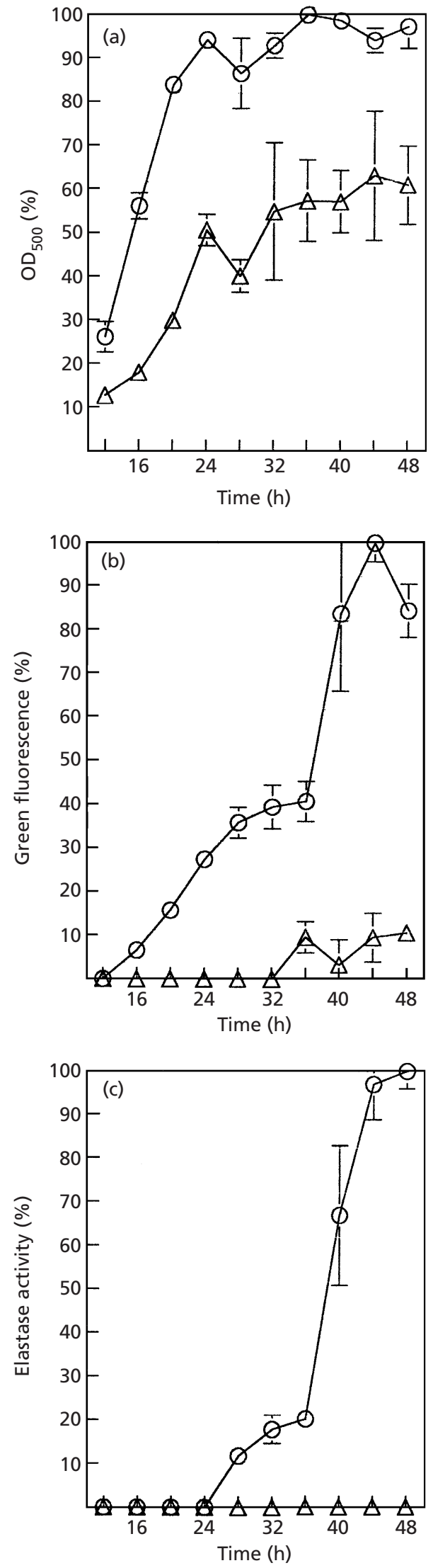

Matthew R. Parsek, personal communication) and supplied to $P$. aeruginosa PAO1 in trans on $\mathrm{pMRP} 17 \mathrm{R}^{-}$ (Table 1), was used to evaluate the activity of the las $B$ promoter. The data from one of two experiments performed with essentially identical results are illustrated in Fig. 1. The LB-grown $P$. aeruginosa PAO1 $\left(\mathrm{pMRP} 17 \mathrm{R}^{-}\right)$cultures entered stationary phase about $24 \mathrm{~h}$ post-inoculation (Fig. 1a). The lasB::gfp fusion was expressed in two cycles. The first cycle of las $B:: g f p-$ directed GFP synthesis began between 12 and $16 \mathrm{~h}$ postinoculation, and continued for about $12 \mathrm{~h}$ (Fig. 1b). The second cycle of GFP synthesis began between 36 and $40 \mathrm{~h}$ post-inoculation, and stopped between 44 and $48 \mathrm{~h}$ post-inoculation (Fig. 1b). The accumulation of active extracellular elastase followed the pattern of las $B:: g f p$ expression, except that extracellular elastase accumulation lagged several hours behind the start of the first cycle of transcription (compare Fig. 1b, c), suggesting either that the lasB::gfp transcriptional fusion does not accurately reflect first cycle las $B$ transcription or that first cycle las $B$ transcripts are post-transcriptionally regulated. Post-transcriptional iron regulation of las $B$ expression has, in fact, been demonstrated (Brumlik \& Story, 1998). In any case, the first cycle of lasB::gfp expression accounted for $40 \%$ of the total GFP synthesis and $20 \%$ of the total elastase activity (compare Fig. 1b, c). The second cycle of lasB::gfp expression and the extracellular accumulation of elastase were essentially simultaneous (compare Fig. 1b, c).

In the presence of $80 \mu \mathrm{M}$ MPPA, $P$. aeruginosa PAO1 also entered stationary phase at about $24 \mathrm{~h}$ postinoculation, and reached a level of growth of about $60 \%$ of the stationary-phase level obtained when grown in LB only, as measured at $\mathrm{OD}_{500}$ (Fig. 1a) and by viable counts $\left[48 \mathrm{~h}\right.$ incubation in LB alone, c.f.u. $\mathrm{ml}^{-1}=$ $5.23 \times 10^{8}\left( \pm 1.70 \times 10^{8}, n=4\right) ; 48 \mathrm{~h}$ incubation in LB + MPPA, c.f.u. $\left.\mathrm{ml}^{-1}=3.35 \times 10^{8}\left( \pm 0.64 \times 10^{8}, n=4\right)\right]$. The expression of las $B:: g f p$, as measured by GFP synthesis, began between 32 and $36 \mathrm{~h}$ post-inoculation, and stopped within $4 \mathrm{~h}$ at a level 10 -fold lower than that observed in cultures grown in LB only (Fig. 1b), despite a less than twofold decrease in the growth yield (Fig. 1a). As in previous experiments, in the presence of $80 \mu \mathrm{M}$ MPPA, active extracellular elastase did not accumulate (Fig. 1c). Therefore, these data suggest that MPPA in the culture medium resulted in the inhibition of las $B$ promoter activity, when compared to cultures grown in LB only.

Fig. 1. (a) Effect of MPPA on P. aeruginosa PAO1 growth. An $\mathrm{OD}_{500}$ value of 1.55 was equivalent to $100 \%$. LB alone, $\bigcirc$; LB + MPPA $(80 \mu \mathrm{M}), \triangle$. (b) Effect of MPPA on lasB::gfp expression. A green fluorescence reading (at $515 \mathrm{~nm}$ ) of 164 was equivalent to $100 \%$. P. aeruginosa PAO1(pMRP17R ${ }^{-}$) cultures were grown in LB $(O)$ and in LB containing $80 \mu \mathrm{M}$ MPPA $(\triangle)$. (c) Effect of MPPA on exoprotease accumulation. A zone of elastase activity of $19.5 \mathrm{~mm}$ (including the $6.5 \mathrm{~mm}$ diameter of the well) in diameter on casein agar plates was equivalent to $100 \%$. LB alone, $\bigcirc$; LB +MPPA $(80 \mu \mathrm{M}), \triangle$. In each graph the data points represent the mean $\pm S D$ for four separate $2 \mathrm{ml}$ static cultures. 
(a)

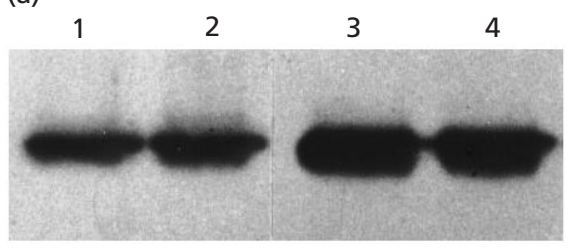

(b)

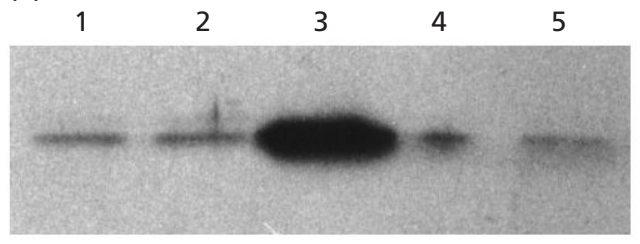

(c)

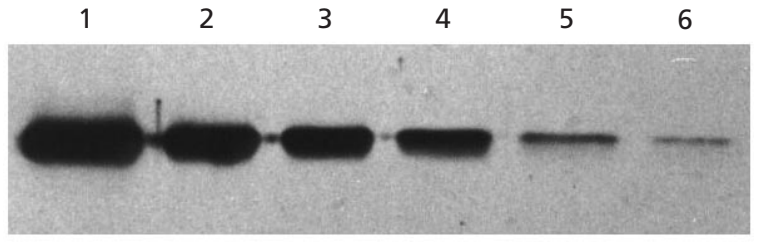

Fig. 2. Immunoblot analysis of $P$. aeruginosa $P A O 1$ elastase production in the presence and absence of MPPA. (a) $P$. aeruginosa PAO1 grown in LB. Lanes 1 and 2, cell extracts from two independent cultures; lanes 3 and 4, cell-free supernatants from the same two independent cultures. (b) $P$. aeruginosa PAO1 grown in LB containing $80 \mu \mathrm{M}$ MPPA. Lanes 1 and 2, cell extracts from two independent MPPA cultures; lane 3, LB cellfree supernatant [same as (a, lane 4)]; lanes 4 and 5, cell-free supernatants from the same two independent MPPA cultures. (c) Immunoblot analysis of serial twofold dilutions of the LB cell-free supernatant of (a, lane 4). Lanes: 1, undiluted; 2, diluted twofold; 3 , diluted fourfold; 4, diluted eightfold; 5, diluted 16 -fold; 6 , diluted 32 -fold.

\section{$P$. aeruginosa PA01 grown in the presence of $80 \mu \mathrm{M}$ MPPA synthesizes a low level of inactive elastase}

Elastase is synthesized as a $53 \mathrm{kDa}$ pre-proenzyme which is processed to a $51 \mathrm{kDa}$ inactive proenzyme as it translocates across the inner membrane (Iglewski et al., 1990 ; Kessler \& Safrin, 1988). Proelastase is then further processed to its mature $33 \mathrm{kDa}$ form in the periplasm, but remains non-covalently bound to its $18 \mathrm{kDa}$ propeptide and remains inactive (Kessler \& Safrin, 1988; Kessler et al., 1998). The propeptide-elastase complex is then secreted from the periplasm across the outer membrane by the $P$. aeruginosa type II general Xcp secretion pathway (Martinez et al., 1998; Tommassen et al., 1992). Elastase is activated extracellularly by degradation of the propeptide (Kessler et al., 1998).

To examine the effect of MPPA on translational and processing events, the relative amounts of intracellular and extracellular elastase in $48 \mathrm{~h}$ static $P$. aeruginosa PAO1 cultures incubated in the presence and absence of
MPPA $(80 \mu \mathrm{M})$ were determined by immunoblotting. Neither intracellular nor extracellular unprocessed preproelastase $(53 \mathrm{kDa})$ and proelastase $(51 \mathrm{kDa})$ were detected in control $P$. aeruginosa PAO1 LB-grown cultures or in cultures grown in the presence of $80 \mu \mathrm{M}$ MPPA (data not shown). In $48 \mathrm{~h}$ LB-grown cultures, the intracellular level of the $33 \mathrm{kDa}$ elastase protein was about $40 \%$ that of the extracellular level (determined by densitometry, also compare Fig. 2a, c). For cultures grown in the presence of MPPA $(80 \mu \mathrm{M})$, intracellular levels of the $33 \mathrm{kDa}$ elastase protein were found to be about $7 \%$ those of the intracellular levels detected in cultures grown in LB (determined by densitometry, also compare Fig. $2 \mathrm{a}-\mathrm{c}$ ). When corrected for differences in growth, the intracellular levels of the $33 \mathrm{kDa}$ elastase protein in the presence of MPPA were $11.7 \%$ of those detected in the LB-grown cultures. Extracellular $33 \mathrm{kDa}$ elastase protein was also detected in cultures grown in the presence of $80 \mu \mathrm{M}$ MPPA, but at levels of about $6 \%$ those detected in supernatants of cultures grown in LB (determined by densitometry, also compare Fig. 2b, c), $10 \%$ when corrected for differences in growth. Thus, it appears that $80 \mu \mathrm{M}$ MPPA inhibited both the intracellular and extracellular accumulation of the $33 \mathrm{kDa}$ elastase protein by about 10 -fold. In addition, it appears that the $33 \mathrm{kDa}$ elastase present in MPPA supernatants was present in an inactive form.

\section{Activation of exoprotease in MPPA-supplemented culture supernatants}

Since LB culture supernatants could be diluted 20- to 30fold and still demonstrated elastase activity on casein agar plates, and since proelastase is thought to be activated by elastase (Kessler et al., 1998), an attempt was made to activate the small amount of inactive elastase in the MPPA culture supernatants by adding low levels of active elastase to supernatants from cells grown in the presence of MPPA. More specifically, cellfree supernatants derived from $P$. aeruginosa PAO1 cultures grown in the presence of $80 \mu \mathrm{M}$ MPPA were treated with a 20-fold-diluted cell-free supernatant derived from a $P$. aeruginosa PAO1 culture grown in LB, incubated for $1 \mathrm{~h}$ at $37^{\circ} \mathrm{C}$ and assayed for proteolytic activity. The 20-fold-diluted cell-free LB supernatant alone showed little protease activity on casein agar plates exclusive of the $6.5 \mathrm{~mm}$ well diameter $(2.70 \pm$ $0.88 \mathrm{~mm}, n=8)$. As expected, no elastase activity was detected in MPPA supernatants. An increase in elastase activity was, however, observed $(P<0.001)$ in the MPPA supernatants that had been treated with the 20 -folddiluted LB cell-free supernatant $(5.53 \pm 1.51 \mathrm{~mm}, n=8)$. The additional elastase activity observed was of the order of $5 \%$ of that normally obtained in LB cultures. No increase in activity was detectable if the MPPA supernatant was heated $\left(100{ }^{\circ} \mathrm{C}\right)$ for $30 \mathrm{~min}$ before addition of the diluted LB supernatant. Similarly, no activation occurred if the LB supernatant was heated before being added to the MPPA supernatant (data not shown). In addition, even when diluted only fivefold, $P$. aeruginosa $\mathrm{PAO}-\mathrm{B} 1$ cell-free supernatants (see above) 


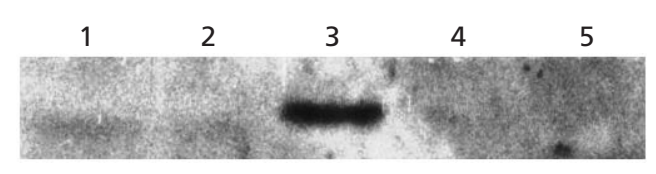

Fig. 3. Immunoblot analysis of $P$. aeruginosa PAO1 LasA production in LB and in LB containing $80 \mu \mathrm{M}$ MPPA. Lanes 1 and 2, cell extracts from two independent MPPA cultures; lane 3 , LB cell-free supernatant; lanes 4 and 5, cell-free supernatants from the same two independent MPPA cultures.

failed to activate inactive elastase in cell-free $P$. aeruginosa PAO1 MPPA supernatants; however, 20-folddiluted LB supernatants of $P$. aeruginosa PAO1 did activate the inactive elastase. Furthermore, cell-free supernatants derived from $P$. aeruginosa PAO1 LBgrown cultures failed to activate $P$. aeruginosa PAO-B1 cell-free supernatants. It therefore appears that the active elastase in LB-grown culture supernatants is what activates inactive elastase in the MPPA supernatants.

To this point, these data suggest that cells grown in the presence of MPPA $(80 \mu \mathrm{M})$ show reduced lasB transcription and correspondingly reduced levels of elastase accumulation. Overall this appears to result in the production of low levels of inactive elastase, which can be activated under the appropriate conditions.

\section{LasA synthesis in the presence of MPPA}

LasA, a second $P$. aeruginosa PAO1 zinc metalloprotease, is thought to be selective for Gly-Ala peptide bonds within Gly-Gly-Ala sequences in elastin (Kessler et al., 1997), and it is required for maximal elastase activity on elastin (Kessler et al., 1997). LasA synthesis is positively regulated by quorum sensing (Brint \& Ohman, 1996; Passador et al., 1993). LasA is synthesized as a $42 \mathrm{kDa}$ proenzyme that is processed extracellularly via a transient $28 \mathrm{kDa}$ intermediate and a $14 \mathrm{kDa}$ propeptide fragment (Kessler et al., 1998). The $28 \mathrm{kDa}$ intermediate is then further processed to the mature $20 \mathrm{kDa}$ LasA protein (Kessler et al., 1998). The relative amounts of intracellular and extracellular LasA protein present in $48 \mathrm{~h}$ LB-grown cultures of $P$. aeruginosa PAO1 and in cultures incubated in the presence of MPPA $(80 \mu \mathrm{M})$ were determined by immunoblotting, using antibodies to LasA. Although $48 \mathrm{~h}$ LB-grown culture supernatants contained amounts of the $20 \mathrm{kDa}$ mature LasA protein that could be diluted fourfold and still be within the detection limit for the immunoblotting procedure, the $20 \mathrm{kDa}$ mature LasA protein was not found in P. aeruginosa PAO1 MPPA cell extracts nor in culture supernatants (Fig. 3). Neither the $42 \mathrm{kDa}$ proenzyme, the $28 \mathrm{kDa}$ intermediate nor the $14 \mathrm{kDa}$ propeptide fragment were found in $48 \mathrm{~h} \mathrm{LB}$-grown P. aeruginosa PAO1 culture cell extracts or in their culture supernatants, neither were they found in the MPPA $P$. aeruginosa $\mathrm{PAO} 1$ culture cell extracts or in their culture supernatants (data not shown). It would appear, therefore, that in addition to inhibiting the intracellular and extracellular accumulation of elastase, MPPA also inhibited the intracellular and extracellular accumulation of the LasA protease.

\section{Alginate synthesis and biofilm formation}

$P$. aeruginosa $\mathrm{PAO} 1$ forms a thick, readily visible biofilm in the menisci of static LB-grown cultures. In the presence of $80 \mu \mathrm{M}$ MPPA, such a biofilm is not apparent. To confirm this observation, biofilm formation was assessed after 28 and $48 \mathrm{~h}$ of incubation using the staining and dye-solubilization assay described by O'Toole et al. (1999). The results shown in Table 3 demonstrate that at 28 and $48 \mathrm{~h}$ post-inoculation in the presence of MPPA growth was inhibited by approximately twofold (55 and $43 \%$ at 24 and 48 h, respectively), whereas biofilm formation was inhibited by almost 10 -fold ( $89 \%$ inhibition) at $28 \mathrm{~h}$ and fourfold ( $73 \%$ inhibition) at $48 \mathrm{~h}$. It is likely that the $48 \mathrm{~h}$ data actually underestimate the level of inhibition on biofilm formation, in as much as the heavy biofilms formed at $48 \mathrm{~h}$ in LB-grown cultures appeared to separate from the sides of the microtitre plates, resulting in somewhat lower levels of staining and dye recovery than were expected.

Since $P$. aeruginosa biofilms form in a matrix of alginate (Baltimore, 1993; Speert et al., 1987), 48 h static P. aeruginosa PAO1 LB-grown cultures and LB + MPPAgrown cultures were tested for alginate production. In two separate experiments, $P$. aeruginosa PAO1 LBgrown cultures produced $24 \cdot 1 \mu \mathrm{g}$ of alginate $(\mathrm{mg}$ cell protein $)^{-1}$ and $37 \cdot 2 \mu \mathrm{g}$ of alginate (mg cell protein) ${ }^{-1}$, respectively, whereas in both experiments $P$. aeruginosa PAO1 grown in the presence of $80 \mu \mathrm{M}$ MPPA produced only $1.2 \mu \mathrm{g}$ of alginate $(\mathrm{mg} \text { cell protein })^{-1}$. Therefore, in addition to inhibiting the accumulation of elastase, LasA protease and pyoverdin, MPPA also inhibited the accumulation of alginate by 20 - to 30 -fold.

\section{O-antigen synthesis in the presence of MPPA}

$P$. aeruginosa strains isolated from cystic fibrosis patients produce reduced levels of exoproteases (Luzar \& Montie, 1985) and O-antigen (Hancock et al., 1983). Since MPPA inhibited the accumulation of pyoverdin, elastase, LasA and alginate, it was of interest to determine whether growth of $P$. aeruginosa PAO1 in the presence of $80 \mu \mathrm{M}$ MPPA had an effect on the Oserotype or on $\mathrm{O}$-antigen synthesis. $P$. aeruginosa $\mathrm{PAO} 1$ grown in static $48 \mathrm{~h} \mathrm{LB}$ cultures and in LB cultures containing $80 \mu \mathrm{M}$ MPPA were tested with 20 polyclonal sera specific to each of the 20 international antigenic typing system (IATS) $\mathrm{O}$-serotypes of $P$. aeruginosa. When grown in either the presence or the absence of MPPA, P. aeruginosa PAO1 serotyped as O2/O5. LPS was also purified from $P$. aeruginosa $\mathrm{PAO} 1$ cells grown in the presence and the absence of $80 \mu \mathrm{M}$ MPPA. This was examined for $\mathrm{O} 5$ antigen by immunoblotting. No major difference was observed in the amount of O5 antigen produced by $P$. aeruginosa PAO1 when grown in the presence or in the absence of MPPA (data not shown). 
Table 3. Effect of MPPA on $P$. aeruginosa PAO1 biofilm formation

All results are the mean for five replicates \pm SD. Cultures were grown statically at $37^{\circ} \mathrm{C}$ in 24 -well microtitre plates. At the indicated times, cells were recovered and the wells were washed and stained with crystal violet.

\begin{tabular}{|lccc|}
\hline Growth medium & Incubation time $(\mathbf{h})$ & Growth $\left(\mathrm{OD}_{\mathbf{5 0 0}}\right)$ & Biofilm $\left(\boldsymbol{A}_{\mathbf{5 8 0}}\right) *$ \\
\hline LB alone & 28 & $1 \cdot 87 \pm 0 \cdot 04$ & $1 \cdot 73 \pm 0 \cdot 36$ \\
LB + MPPA $(80 \mu \mathrm{M})$ & 28 & $0 \cdot 84 \pm 0 \cdot 12$ & $0 \cdot 19 \pm 0 \cdot 12$ \\
LB alone & 48 & $1 \cdot 67 \pm 0 \cdot 13$ & $0 \cdot 45 \pm 0 \cdot 04$ \\
LB + MPPA $(80 \mu \mathrm{M})$ & 48 & $0 \cdot 96 \pm 0 \cdot 01$ & $0 \cdot 12 \pm 0 \cdot 03$ \\
\hline
\end{tabular}

*Biofilm formation is expressed as the recovery (at $A_{580}$ ) of crystal violet following solubilization of the stain in $95 \%$ ethanol.

\section{Autoinducer synthesis in the presence of MPPA}

The data presented above indicate that MPPA has a broad range of inhibitory effects relating to the production of virulence factors by $P$. aeruginosa PAO1. Since the synthesis of elastase and a number of other factors are believed to be regulated by quorum sensing, we speculated that differences in the concentration of signal molecules in the presence and the absence of MPPA could, at least in part, account for the observed differences in the extracellular accumulation of virulence factors. To examine this possibility, signal molecules were extracted at $4 \mathrm{~h}$ intervals between 12 and $48 \mathrm{~h}$ postinoculation from $2 \mathrm{ml}$ cultures of $P$. aeruginosa PAO1 grown statically in LB and in LB containing $80 \mu \mathrm{M}$ MPPA. The concentration of the signal molecules was estimated by means of OdDHL- and BHL-specific indicator bacteria which expressed bioluminescence in a concentration-dependent manner. The data from one of two experiments performed with essentially identical results are illustrated in Fig. 4. Extracellular BHL began to accumulate between 12 and $16 \mathrm{~h}$ post-inoculation in LB-grown cultures, and accumulation peaked at about $20 \mathrm{~h}$ post-inoculation. The BHL level dropped thereafter (Fig. 4). Extracellular OdDHL began to accumulate between 16 and $20 \mathrm{~h}$ post-inoculation in LB-grown cultures, and its accumulation levelled off at about $28 \mathrm{~h}$ post-inoculation (Fig. 4). In the presence of $80 \mu \mathrm{M}$ MPPA, the extracellular levels of both OdDHL and BHL reached LB-grown culture levels; however, the extracellular appearance of each lactone was delayed by about $8 \mathrm{~h}$, relative to the LB control (Fig. 4). Therefore, enough OdDHL and BHL accumulated in $P$. aeruginosa PAO1 cultures grown in the presence of MPPA to stimulate lasB:: $g f p$ transcription. The failure of OdDHL and BHL to do so suggests either that these signal molecules are unable to re-enter $P$. aeruginosa PAO1 cells grown in the presence of $80 \mu \mathrm{M}$ MPPA or that las $B:: g f p$ transcription is inhibited because other regulators required for las $B$ expression are affected by MPPA.

It might be argued that since OdDHL and BHL appear about $8 \mathrm{~h}$ later in MPPA-supplemented cultures than they do in LB-grown cultures, there has not been sufficient time for the expression of lasB in the MPPA- supplemented cultures when assayed at $48 \mathrm{~h}$ postincubation. However, when the incubation period for MPPA cultures of $P$. aeruginosa PAO1 was extended to $72 \mathrm{~h}$, las $B:: g f p$ expression remained at the same level as in the $48 \mathrm{~h}$ MPPA cultures, and elastase was still undetectable in the cell-free supernatants (data not shown). In addition, when, at $24 \mathrm{~h}$ post-inoculation, $P$. aeruginosa $\mathrm{PAO} 1$ cultures were centrifuged, resuspended in the $2 \mathrm{ml}$ of LB in which they were grown and incubated for an additional $24 \mathrm{~h}$, no effect on pyoverdin or elastase accumulation, or on lasB::gfp expression was observed. In contrast, centrifugation and resuspension of $24 \mathrm{~h} \mathrm{LB}$-grown cultures in LB containing $80 \mu \mathrm{M}$ MPPA limited lasB::gfp expression and pyoverdin accumulation to $30 \%$ and elastase accumulation to $6 \%$ of the levels of LB cultures at $48 \mathrm{~h}$ (data not shown). In other words, MPPA is effective in blocking virulence factor synthesis, even when $P$. aeruginosa PAO1 has been incubated in LB for $24 \mathrm{~h}$. Finally, when at $24 \mathrm{~h}$ post-inoculation $P$. aeruginosa PAO1 growing in MPPA culture medium was centrifuged, resuspended in $24 \mathrm{~h}$ MPPA culture medium to cell densities equal to those present in $48 \mathrm{~h} \mathrm{LB}$ cultures and incubated for an additional $24 \mathrm{~h}$, elastase still failed to accumulate, las $B:: g f p$ expression was still inhibited and pyoverdin accumulation was still reduced (data not shown), indicating that in MPPA cultures a reduction in $P$. aeruginosa PAO1 density alone was not responsible for the lack of response to the presence of OdDHL and BHL.

\section{RpoS plays no role in the MPPA-mediated inhibition of the accumulation of alginate, pyoverdin and elastase}

RpoS, the stationary phase $\sigma$ factor, regulates the expression of a number of $P$. aeruginosa PAO1 genes, the products of which confer increased tolerance to various forms of stress (Suh et al., 1999). Expression of the $P$. aeruginosa $\mathrm{PAO} 1 \mathrm{rpoS}$ gene increases as cultures reach stationary phase (Whiteley et al., 2000). Moreover, $P$. aeruginosa $\mathrm{PAO} 1 \mathrm{rpoS}$ mutants have been reported to accumulate increased levels of pyoverdin, pyocyanin and BHL (Suh et al., 1999; Whiteley et al., 2000). To 

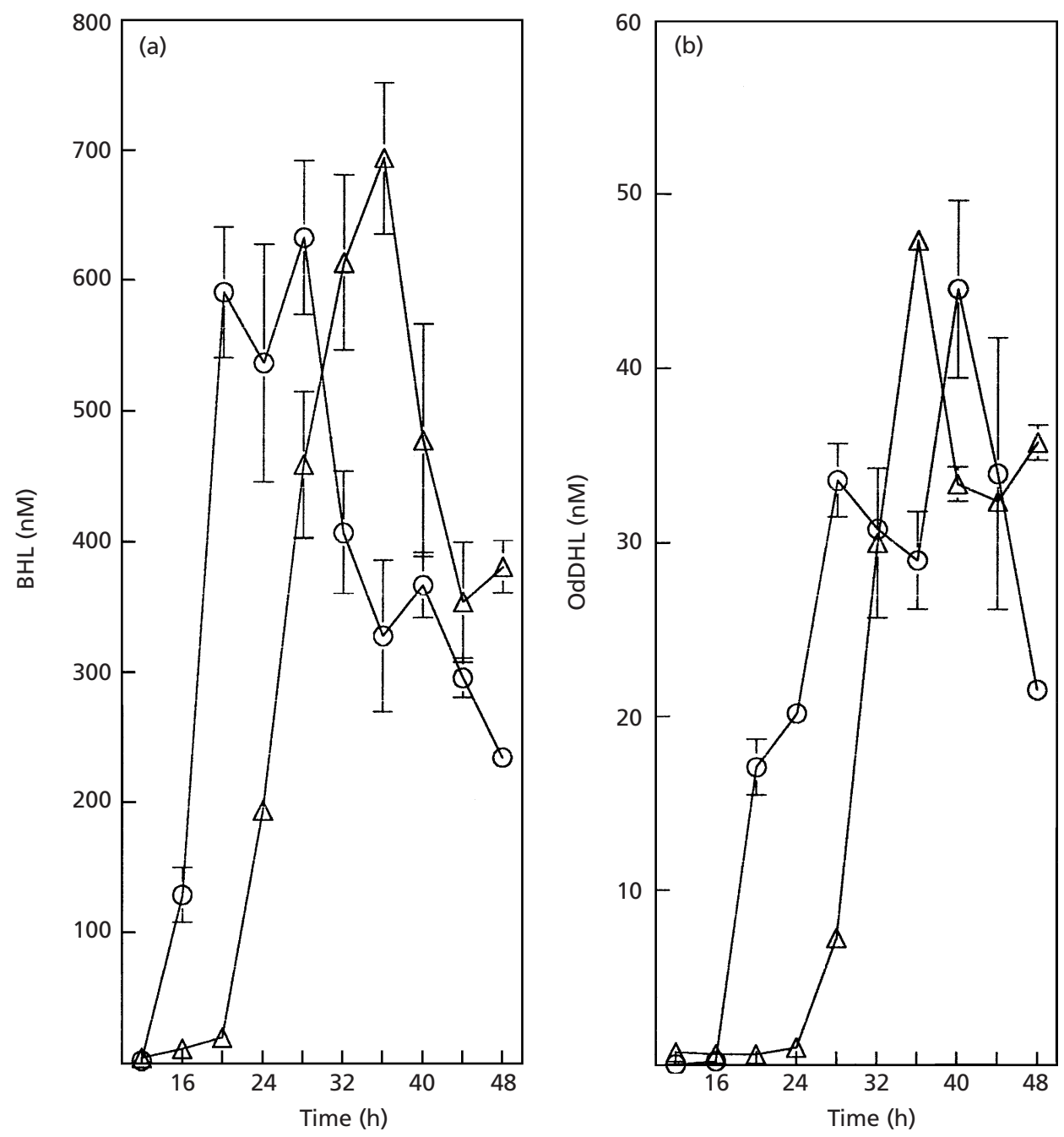

Fig. 4. Kinetics of synthesis of $B H L(a)$ and $O d D H L(b)$ in $P$. aeruginosa $P A O 1$ LB-grown cultures $(O)$ and in $P$. aeruginosa PAO1 cultures grown in LB containing $80 \mu \mathrm{M}$ MPPA $(\triangle)$. Data are presented as the mean \pm SD for three separate cultures.

determine whether the expression of $r p o S$ was involved in the MPPA-induced inhibition of virulence factor production, $P$. aeruginosa $\mathrm{PAO}-\mathrm{MW} 20$, a $P$. aeruginosa PAO1 rpoS mutant, was grown in $2 \mathrm{ml}$ static cultures for $48 \mathrm{~h}$ and the effects of $80 \mu \mathrm{M}$ MPPA on growth and on alginate, pyoverdin and elastase production were determined. Although PAO-MW20 appeared to be less susceptible to the growth-inhibiting effects of MPPA $\left(\mathrm{LB}, \mathrm{OD}_{500}=1.50 \pm 0.08, n=5 ; \mathrm{MPPA}, \mathrm{OD}_{500}=1.33 \pm\right.$ $0 \cdot 05, n=5)$, pyoverdin production was inhibited by about $65 \% \quad\left(\mathrm{LB}, A_{380}=3 \cdot 12 \pm 0 \cdot 22, n=5 ; \mathrm{MPPA}\right.$, $\left.A_{380}=1.07 \pm 0.08, n=5\right)$, alginate production was reduced by more than 10 -fold [LB, $44 \cdot 9$ (experiment 1 ) and 68.3 (experiment 2); MPPA, 0.59 (experiment 1 ) and 6.1 (experiment 2 ); results expressed as $\mu$ g alginate (mg cell protein $)^{-1}$ ] and elastase was essentially completely inhibited (LB diameter of zone of casein hydrolysis, $22.5 \pm 0.39 \mathrm{~mm}, n=5$; MPPA, no detectable activity, $n=5$; MPPA upon activation, about $2 \%$ of LB activity, i.e. $9 \cdot 06 \pm 0.05 \mathrm{~mm}, n=5$ ). While the data suggest a role for $r p o S$ expression in limiting the growth of $P$. aeruginosa PAO1 in the presence of MPPA, it would appear that rpoS expression plays no role in the MPPAmediated inhibition of pyoverdin, elastase and alginate accumulation.

\section{Effect of the addition of calcium, iron, magnesium and zinc to LB containing MPPA}

MPPA binds divalent cations in LB (Krogfelt et al., 2000). LB contains $10 \cdot 4 \mu \mathrm{M}$ zinc (see Methods), $7 \cdot 2 \mu \mathrm{M}$ iron (see Methods), $263 \mu \mathrm{M}$ calcium (Krogfelt et al., 2000) and $225 \mu \mathrm{M}$ magnesium (Krogfelt et al., 2000). In the presence of $80 \mu \mathrm{M}$ MPPA, the zinc concentration in $\mathrm{LB}$ is reduced to $5 \cdot 7 \mu \mathrm{M}$ (see Methods), the calcium concentration is reduced to $167 \mu \mathrm{M}$ (Krogfelt et al., 2000), the magnesium concentration is reduced to $128 \mu \mathrm{M}$ (Krogfelt et al., 2000) and the iron concentration is reduced to $3.6 \mu \mathrm{M}$ (see Methods). In the presence of $80 \mu \mathrm{M} \mathrm{MPPA}$, the transcription of las $B:: g f p$, as measured by GFP synthesis, was reduced to about $38 \%$ of the LB culture control level when corrected for growth, 
Table 4. The effect of the addition of calcium $(100 \mu \mathrm{M})$, iron $(10 \mu \mathrm{M})$, magnesium $(100 \mu \mathrm{M})$ and zinc $(100 \mu \mathrm{M})$ on $P$. aeruginosa $\mathrm{PAO} 1\left(\mathrm{pMRP} 17 \mathrm{R}^{-}\right)$growth, pyoverdin production, las $B:: g f p$ expression and elastase activity in the presence of MPPA $(80 \mu \mathrm{M})$

Cultures $(2 \mathrm{ml})$ were grown statically at $37^{\circ} \mathrm{C}$. Values of $100 \%$ for growth, pyoverdin production and elastase activity are essentially as in the legend to Table 2, and the $100 \%$ value for lasB::gfp expression (fluorescence at $515 \mathrm{~nm}$ ) is 291 .

\begin{tabular}{|c|c|c|c|c|}
\hline LB plus & $\begin{array}{c}\text { Growth } \\
(\% \text { of } L B)^{*}\end{array}$ & $\begin{array}{c}\text { Pyoverdin } \\
(\% \text { of LB per cell }) \dagger \neq\end{array}$ & $\begin{array}{c}\text { lasB: }:: g f p \\
(\% \text { of LB per cell }) \mathbb{S} \neq\end{array}$ & $\begin{array}{c}\text { Elastase activity } \\
(\% \text { of LB per cell }) \| \neq\end{array}$ \\
\hline No additions & $100 \pm 5 \cdot 569$ & $100 \pm 10 \cdot 79$ & $100 \pm 18 \cdot 1$ & $100 \pm 3 \cdot 759$ \\
\hline MPPA & $60 \cdot 0 \pm 7 \cdot 809$ & $55 \cdot 2 \pm 19 \cdot 69$ & $37 \cdot 5 \pm 16 \cdot 99$ & 09 \\
\hline $\mathrm{MPPA}+\mathrm{Ca}^{2+}+\mathrm{Fe}^{2+}+\mathrm{Mg}^{2+}+\mathrm{Zn}^{2+}$ & $110 \pm 4 \cdot 46 \#$ & $73 \cdot 9 \pm 6 \cdot 8 \#$ & $91 \cdot 1 \pm 23 \cdot 5 \#$ & $111 \pm 14 \cdot 7 \#$ \\
\hline \multicolumn{5}{|l|}{${ }^{*} \mathrm{OD}_{500}$ of $48 \mathrm{~h}$ cultures. } \\
\hline \multicolumn{5}{|c|}{$\dagger A_{380}$ of $48 \mathrm{~h}$ cultures. } \\
\hline \multicolumn{5}{|c|}{$\ddagger \%$ of LB per cell was calculated as a percentage of the LB raw data value divided by the fractional growth relative to LB. } \\
\hline \multicolumn{5}{|c|}{ \$Fluorescence (at $515 \mathrm{~nm}$ ). } \\
\hline \multicolumn{5}{|l|}{ || Casein hydrolysis on casein agar plates. } \\
\hline \multicolumn{5}{|l|}{ 9 $n=13$} \\
\hline \multicolumn{5}{|l|}{$\# n=6}$. \\
\hline
\end{tabular}

pyoverdin accumulation was reduced to $55 \%$ of the LB level and elastase was undetectable (Table 4). When LB containing $80 \mu \mathrm{M}$ MPPA was supplemented with ferrous sulfate $(10 \mu \mathrm{M})$, calcium chloride $(100 \mu \mathrm{M})$, magnesium chloride $(100 \mu \mathrm{M})$ and zinc chloride $(100 \mu \mathrm{M})$, P. aeruginosa PAO1 growth levels returned to LB levels, pyoverdin accumulated at about $75 \%$ of the LB levels, lasB:: $g f p$ expression was about $90 \%$ of the LB levels and the extracellular accumulation of active elastase returned to the LB levels (Table 4). It therefore appears that the effects of MPPA on P. aeruginosa PAO1 can be reversed to a large extent by supplementing the medium with divalent cations.

\section{Effect of EDTA on P. aeruginosa PAO1 growth, and on pyoverdin and elastase synthesis}

Since EDTA chelates divalent cations and the effects of MPPA on the extracellular accumulation of pyoverdin and elastase appeared to be due, at least in part, to MPPA binding divalent cations, EDTA was tested for its ability to inhibit las $B:: g f p$ expression and the accumulation of pyoverdin and elastase. P. aeruginosa PAO1 failed to accumulate active extracellular elastase in the presence of between 32 and $64 \mu \mathrm{M}$ EDTA, depending on the experiment (data not shown). To ensure the inhibition of the extracellular accumulation of elastase, EDTA was used at a concentration of $125 \mu \mathrm{M}$ in succeeding experiments. EDTA decreased $P$. aeruginosa PAO1 growth by about $15 \%$ and lasB:: $g f p$ expression by about fourfold, and it completely prevented the accumulation of active elastase (Table 5). Immunoblot analysis showed that the elastase protein was present in EDTA supernatants at levels 5-10\% those of the LB supernatants (data not shown). In contrast to MPPA, however, EDTA did not inhibit pyoverdin production and, in fact, caused about a $30 \%$ increase in its production $(P<0.05)$ (Table 5$)$. The addition of magnesium $(125 \mu \mathrm{M})$, calcium $(125 \mu \mathrm{M})$, zinc $(125 \mu \mathrm{M})$ and iron $(10 \mu \mathrm{M})$ to the growth medium reversed the effect of the presence of EDTA on growth, much of its effect on las $B:: g f p$ expression, and allowed the accumulation of extracellular elastase (Table 5). Therefore, EDTA appears to mimic the effect of MPPA on lasB::gfp transcription and on the accumulation of extracellular elastase, but unlike MPPA, it does not inhibit the accumulation of extracellular pyoverdin.

\section{Effect of MPPA on the cellular and extracellular protein content of $P$. aeruginosa PAO1}

Experiments were performed to determine whether the growth of $P$. aeruginosa PAO1 in the presence of MPPA resulted in an excessive release of cellular proteins into the culture supernatant between 24 and 48 h of growth relative to the LB-grown cultures, as might be expected if, for example, MPPA induced cell lysis. In LB-grown cultures, the cellular protein content increased from about $170 \mu \mathrm{g}(\mathrm{ml} \text { culture })^{-1}$ to $220 \mu \mathrm{g}(\mathrm{ml} \text { culture })^{-1}$ between 24 and $30 \mathrm{~h}$ of incubation and remained constant thereafter. Between 24 and 36 h of incubation, the extracellular protein content for the LB-grown cultures increased from about $25 \%$ of the cellular protein level to about $50 \%$ of the cellular protein level, and it was still at this level after $48 \mathrm{~h}$ of incubation. This result was not unexpected, since $P$. aeruginosa PAO1 secretes numerous proteins involved in its pathogenesis (Howe \& Iglewski et al., 1984; Nicas et al., 1985; Preston et al., 1997; Woods et al., 1982; Vasil et al., 1993) as well as membrane vesicles containing virulence factors (Kadurugamuwa \& Beveridge, 1997). Between 24 and $36 \mathrm{~h}$ of incubation in the presence of $80 \mu \mathrm{M} \mathrm{MPPA}$, the cellular protein content remained constant at about $90 \mu \mathrm{g}(\mathrm{ml} \text { culture })^{-1}$; between 36 and $48 \mathrm{~h}$ of incubation 
Table 5. The effect of calcium $(100 \mu \mathrm{M})$, iron $(10 \mu \mathrm{M})$, magnesium $(100 \mu \mathrm{M})$ and zinc $(100 \mu \mathrm{M})$ on $P$. aeruginosa PAO1(pMRP17R-) growth, pyoverdin production, lasB::gfp expression and elastase activity in the presence of EDTA $(125 \mu \mathrm{M})$

Cultures $(2 \mathrm{ml})$ were grown statically at $37^{\circ} \mathrm{C}$. Values of $100 \%$ for growth, pyoverdin production and elastase activity are essentially as in the legend to Table 2, and the $100 \%$ value for lasB::gfp expression (fluorescence at $515 \mathrm{~nm}$ ) is 291 .

\begin{tabular}{|c|c|c|c|c|}
\hline LB plus & $\begin{array}{c}\text { Growth } \\
(\% \text { of LB })^{*}\end{array}$ & $\begin{array}{c}\text { Pyoverdin } \\
(\% \text { of LB per cell }) \dagger \neq\end{array}$ & $\begin{array}{c}\text { lasB:: } g f p \\
(\% \text { of LB per cell }) \mathbb{S} \neq\end{array}$ & $\begin{array}{c}\text { Elastase activity } \\
(\% \text { of LB per cell }) \| \ddagger\end{array}$ \\
\hline No additions & $100 \pm 4 \cdot 529$ & $100 \pm 6 \cdot 069$ & $100 \pm 5 \cdot 04$ & $100 \pm 30 \cdot 5$ \\
\hline EDTA & $84 \cdot 5 \pm 7 \cdot 449$ & $127 \pm 14.99$ & $27 \cdot 1 \pm 10 \cdot 99$ & 09 \\
\hline $\mathrm{EDTA}+\mathrm{Ca}^{2+}+\mathrm{Fe}^{2+}+\mathrm{Mg}^{2+}+\mathrm{Zn}^{2+}$ & $128 \pm 6 \cdot 039$ & $82 \cdot 6 \pm 11 \cdot 69$ & $61 \cdot 0 \pm 7 \cdot 139$ & $103 \pm 19 \cdot 29$ \\
\hline \multicolumn{5}{|l|}{$* \mathrm{OD}_{500}$ of $48 \mathrm{~h}$ cultures. } \\
\hline \multicolumn{5}{|c|}{$\dagger A_{380}$ of $48 \mathrm{~h}$ cultures. } \\
\hline \multicolumn{5}{|c|}{$\ddagger \%$ of LB per cell was calculated as a percentage of the LB raw data value divided by the fractional growth relative to LB. } \\
\hline \multicolumn{5}{|c|}{ \Fluorescence (at $515 \mathrm{~nm}$ ). } \\
\hline \multicolumn{5}{|l|}{ |l Casein hydrolysis on casein agar plates. } \\
\hline 9 $n=6$ & & & & \\
\hline
\end{tabular}

the cellular protein content increased by about $40 \%$, to $130 \mu \mathrm{g}(\mathrm{ml} \text { culture })^{-1}$, i.e. to about $60 \%$ of the $48 \mathrm{~h} \mathrm{LB}$ grown culture cellular protein content. Between 24 and $36 \mathrm{~h}$ of incubation, the extracellular protein content in the MPPA cultures increased from a negligible amount to about $22 \%$ of the cellular protein level, and remained at about this level 36 and $48 \mathrm{~h}$ post-inoculation. Therefore, relative to cellular protein, $P$. aeruginosa PAO1 cells grown in LB released twice the amount of extracellular proteins as cells grown in the presence of MPPA, contrary to what would be expected if cells grown in the presence of MPPA were leaking proteins or were lysing.

\section{DISCUSSION}

In the present investigation we have shown that the lysophospholipid MPPA exerts a broad range of inhibitory effects on the production of factors associated with virulence in $P$. aeruginosa $\mathrm{PAO} 1$, when present at a concentration of $80 \mu \mathrm{M}$ in the growth medium. The concentration of lysophosphatidic acid in bovine foetal calf serum has been reported to be $20 \mu \mathrm{M}$ (Ediger \& Toews, 2001); therefore, the inhibitory effects observed in this study are at concentrations of MPPA only two- to fourfold higher than normal physiological concentrations. The effects of this concentration of MPPA include the inhibition of biofilm formation and inhibition of the extracellular accumulation of elastase, LasA protease, pyoverdin and alginate. In the case of elastase, its inhibition appears to be due to a decrease in las $B$ transcription (about a threefold decrease when a correction is made for differences in growth between the LB and MPPA cultures; Fig. 1 and Table 4), which is accompanied by a decrease in the amount of cellular and extracellular elastase protein that is accumulated (about a 10-fold decrease; Figs 1 and 2, and Table 4).

Previous studies have shown that a variety of ions are involved in regulating virulence factor gene expression and in the efficient production and processing of virulence factors in P. aeruginosa (Brumlick \& Storey, 1992; Cox, 1993; Hofte et al., 1993; Olson \& Ohman, 1992; Rossbach et al., 2000; Vasil \& Ochsner, 1999). In addition, MPPA has been shown to bind divalent cations (Krogfelt et al., 2000). In LB containing $80 \mu \mathrm{M}$ MPPA, the calcium, iron, magnesium and zinc concentrations are reduced by $50-60 \%$ relative to the concentrations of the same divalent cations in LB (see Methods and Krogfelt et al., 2000). Replenishing MPPA cultures with magnesium, calcium, iron and zinc restored their growth, their las $B:: g f p$ expression and their extracellular accumulation of elastase and pyoverdin to levels close to those of the LB-grown cultures (Table 4), suggesting that the effects of MPPA are due, at least in part, to its ability to bind divalent cations.

EDTA $(125 \mu \mathrm{M})$ also inhibited lasB : : gfp expression and the accumulation of extracellular elastase (Table 5); however, unlike MPPA, EDTA stimulated rather than inhibited the extracellular accumulation of pyoverdin. EDTA chelates zinc about $10^{2}$-fold better than it does iron $\left(\mathrm{Fe}^{2+}\right)$, about $10^{6}$-fold better than it does calcium and about $10^{8}$-fold better than it does magnesium (Hodgins, 1961). Therefore, at an EDTA concentration of $125 \mu \mathrm{M}$ it would be expected that all of the zinc $(10 \cdot 4 \mu \mathrm{M})$ and iron $(7 \cdot 2 \mu \mathrm{M})$, about $45 \%$ of the calcium $(117 \mu \mathrm{M})$ and none of the magnesium would be chelated. It might therefore be that the inhibition of pyoverdin accumulation in the presence of MPPA, but not in the presence of EDTA, is due to the differences in the cation concentrations in the two culture media. A detailed study of the effect of individual divalent cation additions to LB containing either MPPA or EDTA on the accumulation of $P$. aeruginosa PAO1 extracellular virulence factors will be the subject of a future communication.

While it appears that divalent cations can reverse or compensate for the inhibitory effects of MPPA, since 
lysophosphatidic acid is known to insert into membranes (Christiansen \& Carlsen, 1983), the possibility that MPPA may inhibit the accumulation of extracellular virulence factors by physically disrupting the $P$. aeruginosa PAO1 membrane structure cannot be excluded. Such membrane disruption could affect cellular secretory processes in general or alter the response of the bacterium to environmental signals.

The transcription of $l a s B$ is positively regulated by RpoS, and by the las R lasI and $r h l R$ rhlI quorum-sensing systems at high cell densities (Brint \& Ohman, 1996; Gambello \& Iglewski, 1991; Passador et al., 1993; Pearson et al., 1994; Suh et al., 1999; Whiteley et al., 1999, 2000). However, the inhibition of lasB expression by MPPA can not be explained by the small reduction in $P$. aeruginosa PAO1 growth in the presence of MPPA, since increasing the cell density did not reverse the effects of MPPA. Neither can it be explained by the amounts of OdDHL and BHL synthesized, since, in the presence of MPPA, OdDHL and BHL accumulation in culture supernatants was normal (Fig. 4). It is possible, however, that in the presence of MPPA, the signal molecules were unable to re-enter $P$. aeruginosa PAO1. Although there is, as yet, no evidence to support this hypothesis, if true, OdDHL and BHL would not be able to interact with their cognate R-proteins. As a consequence, the signals could fail to fully activate the transcription of their target genes. Experiments designed to test this hypothesis are presently under way. Similarly, it appears that the effect of MPPA on the production of $P$. aeruginosa $\mathrm{PAO} 1$ virulence factors does not involve rpoS expression, since in PAO-MW20 cultures incubated in the presence of MPPA, the levels of pyoverdin, elastase and alginate production were all inhibited to the same extent as in P. aeruginosa PAO1 cultures.

At the present time, it is unclear as to why the elastase protein accumulates to a level of only about $10 \%$ of that seen in LB in the presence of MPPA (Fig. 2) when the las $B:: g f p$ fusion is expressed at a level of $38 \%$ of that observed in LB (Table 4). However, it should be noted that the las $B:: g f p$ fusion used here is a transcriptional fusion that may not accurately reflect the degree to which the rate of transcription of the wild-type las $B$ gene in the presence of MPPA is reduced relative to its absence or the rate at which it is translated. Nevertheless, the data show that the las $B$ promoter is about threefold less active when $P$. aeruginosa PAO1 is grown in the presence of MPPA than when it is grown in LB only.

Our interest in MPPA originated from the finding that it enhances the activity of $\beta$-lactam antibiotics against $P$. aeruginosa PAO1 and against $P$. aeruginosa strains isolated from cystic fibrosis patients (Krogfelt et al., 2000). MPPA is a member of a class of phospholipids called lysophosphatidic acids, which contain one fatty acid esterified to the $\mathrm{C} 1$ atom of the glycerol moiety, but which are lacking the fatty acid normally esterified to the C2 atom of the glycerol moiety. Lysophosphatidic acids are believed to be generated from the phosphatidic acid present in the inner leaflet of damaged cell membranes (Fourcade et al., 1998) by secretory phospholipase A2, which accumulates in inflammatory exudates (Paya et al., 1996). Lysophosphatidic acids have recently been implicated in blocking neutrophil recruitment to damaged lung tissue (Abraham et al., 1995) and in inhibiting the metabolic burst of human neutrophils (Chettibi et al., 1994). MPPA may therefore be viewed as a natural anti-inflammatory agent.

It has been suggested that during the initial stages of infection with $P$. aeruginosa, antibodies to $\mathrm{O}$-antigen, extracellular proteases and other virulence factors are synthesized, and these then interact with their cognate antigens to form immune complexes in the lungs of cystic fibrosis patients (Kronborg, 1995). The immune complexes, in turn, attract polymorphonuclear leukocytes (PMNLs) (Kronborg, 1995). The PMNLs then release elastase, cathepsin, oxygen radicals, etc., which leads to the initial inflammation and tissue damage (Kronborg, 1995; Kronborg et al., 1992). Later on, when chronic infection sets in and P. aeruginosa is protected against phagocytosis by biofilm formation, PMNLs continue to infiltrate the lungs and, in attempting to eradicate the infection, cause further inflammation and tissue damage (Kronborg, 1995; Kronborg et al., 1992). Therefore, in infected cystic fibrosis patients, when the lung is relatively healthy, it appears likely that $P$. aeruginosa would synthesize high levels of pyoverdin, elastase and LasA protease, thereby initiating inflammation and tissue damage. Extensive tissue damage would lead to increased levels of lysophosphatidic acids in inflammatory exudates which might lower the local divalent cation concentrations. Low divalent cation concentrations could then result in inhibition of the extracellular accumulation of $P$. aeruginosa pyoverdin, elastase and the LasA protease, in the inhibition of the further recruitment of PMNLs to the site of infection and in the prevention of the metabolic burst of those PMNLs that are already present. When the tissue is repaired and the lysophosphatidic acid concentration is reduced, the synthesis of pyoverdin, elastase and the LasA protease would resume, PMNLs would be recruited and the cycle would repeat. If this scenario is correct, it may be that treating cystic fibrosis patients with MPPA will limit the deleterious effects of chronic infection by reducing inflammation and by limiting the extracellular accumulation of $P$. aeruginosa pyoverdin, elastase and the LasA protease. In addition, since MPPA inhibits the accumulation of alginate, it might reduce $P$. aeruginosa biofilm formation in the lung, making the infection more amenable to antibiotic treatment. Furthermore, if high enough concentrations of MPPA can be achieved in the lungs, its ability to enhance the activities of $\beta$-lactam antibiotics (Krogfelt et al., 2000) might help to limit infection. However, it should be noted that one limiting factor in the use of MPPA in the lungs may be that the concentration of calcium in the sputum of cystic fibrosis patients is $0.7 \mathrm{mM}$, about 2.5 fold higher than in LB, and the sputum concentration of magnesium is $1.2 \mathrm{mM}$, about $5 \cdot 3$-fold higher than in LB (Halmerbauer et al., 2000). Animal experiments, pre- 
sently in progress, should tell us whether MPPA shows clinical promise.

\section{ACKNOWLEDGEMENTS}

This study was supported by a grant to P.S.C. from the University of Rhode Island Foundation and by grants from the Danish Medical and Technical Research Councils to M.G. We thank Dr B. H. Iglewski (Department of Microbiology and Immunology, University of Rochester School of Medicine and Dentistry, Rochester, New York, USA) and Dr E. P. Greenberg (Department of Microbiology, University of Iowa, Iowa City, Iowa, USA) for their kind gifts of bacterial strains, and Dr M. R. Parsek (North Western University, Evanston, Illinois, USA) for his kind gift of $\mathrm{pMRP} 17 \mathrm{R}^{-}$.

\section{REFERENCES}

Abraham, E., Bursten, S., Shenkar, R. \& 7 other authors (1995). Phosphatidic acid signaling mediates lung cytokine expression and lung inflammatory injury after hemorrhage in mice. $J$ Exp Med 18, 569-575.

Baltimore, R. S. (1993). Mucoid colony variants: the exopolysaccharide of Pseudomonas aeruginosa and microcolony formation. In Pseudomonas aeruginosa the Opportunist: Pathogenesis and Disease, pp. 26-40. Edited by R. B. Fick, Jr. Boca Raton, FL: CRC Press.

Bodey, G. P., Bolivar, R., Fainstein, V. \& Jadeja, L. (1983). Infections caused by Pseudomonas aeruginosa. Rev Infect Dis $\mathbf{5}$, 279-313.

Brint, J. M. \& Ohman, D. E. (1996). Synthesis of multiple exoproducts in Pseudomonas aeruginosa is under the control of RhlR-RhlI, another set of regulators in strain PAO1 with homology to the autoinducer-responsive LuxR-LuxI family. J Bacteriol 177, 7155-7163.

Brumlik, M. J. \& Storey, D. G. (1992). Zinc and iron regulate translation of the gene encoding Pseudomonas aeruginosa elastase. Mol Microbiol 6, 337-344.

Brumlik, M. J. \& Storey, D. G. (1998). Post-transcriptional control of Pseudomonas aeruginosa lasB expression involves the $5^{\prime}$ untranslated region of the mRNA. FEMS Microbiol Lett 159, 233-239.

Charlton, T. S., de Nys, R., Netting, A., Kumar, N., Hentzer, M., Givskov, M. \& Kjelleberg, S. (2000). A novel and sensitive method for the quantification of $\mathrm{N}$-3-oxoacyl homoserine lactones using gas chromatography-mass spectrometry: application to a model bacterial biofilm. Environ Microbiol 2, 530-541.

Chettibi, S., Sawrence, A. J., Stevenson, R. D. \& Young, J. D. (1994). Effect of lysophosphatidic acid on motility, polarisation, and metabolic burst of human neutrophils. FEMS Immunol Med Microbiol 8, 271-281.

Christiansen, K. \& Carlsen, J. (1983). Reconstitution of a protein into lipid vesicles using natural detergents. Biochim Biophys Acta 735, 225-233.

Clark, D. J. \& Maaløe, O. (1967). DNA replication and the division cycle in Escherichia coli. J Mol Biol 23, 99-112.

Costerton, J. W., Cheng, K. J., Geesey, G. G., Ladd, T. I., Nickel, J. C., Dasgupta, M. \& Marrie, T. J. (1987). Bacterial biofilms in nature and disease. Annu Rev Microbiol 41, 435-464.

Cox, C. D. (1993). Iron and the virulence of Pseudomonas aeruginosa. In Pseudomonas aeruginosa the Opportunist: Pathogenesis and Disease, pp. 41-58. Edited by R. B. Fick, Jr. Boca Raton, FL: CRC Press.
Coyne, M. J., Jr, Russell, K. S., Coyle, C. L. \& Goldberg, J. B. (1994). The Pseudomonas aeruginosa algC gene encodes phosphoglucomutase, required for the synthesis of a complete lipopolysaccharide core. J Bacteriol 176, 3500-3507.

Cryz, S. J., Jr, Pitt, T. L., Furer, E. \& Germanier, R. (1984). Role of lipopolysaccharide in virulence of Pseudomonas aeruginosa. Infect Immun 44, 508-513.

Davies, D., Parsek, M., Pearson, J., Iglewski, B., Costerton, J. \& Greenberg, E. (1998). The involvement of cell-to-cell signals in the development of a bacterial biofilm. Science 280, 295-298.

Ediger, T. L. \& Towes, M. L. (2001). Dual effects of lysophosphatidic acid on human airway smooth muscle cell proliferation and survival. Biochim Biophys Acta 1531, 59-67.

Fourcade, O., Le Balle, F., Fauvel, J., Simon, M. F. \& Chap, H. (1998). Regulation of secretory type-II phospholipase A2 and of lysophosphatidic acid synthesis. Adv Enzyme Regul 38, 99-107.

Gallagher, S. R. (1999). One-dimensional SDS gel electrophoresis of proteins. In Current Protocols in Molecular Biology, pp. 10.2A.1-10.2A.34. New York: Wiley.

Gallagher, S., Winston, S. E., Fuller, S. A. \& Hurrell, J. G. R. (1997). Immunoblotting and immunodetection. In Current Protocols in Molecular Biology, pp. 10.8.1-10.8.21. New York: Wiley.

Gambello, M. J. \& Iglewski, B. H. (1991). Cloning and characterization of the Pseudomonas aeruginosa lasR gene: a transcriptional activator of elastase expression. J Bacteriol 173, 3000-3009.

Haas, B., Kraut, J., Marks, J., Zanker, S. C. \& Castignetti, D. (1991). Siderophore presence in sputa of cystic fibrosis patents. Infect Immun 59, 3997-4000.

Halmerbauer, G., Arri, S., Schierl, M., Strauch, E. \& Koller, D. Y. (2000). The relationship of eosinophil granule proteins to ions in the sputum of patients with cystic fibrosis. Clin Exp Allergy 30, 1771-1776.

Hancock, R. E. W., Mutharia, L. M., Chan, L., Darveau, R. P., Speert, D. P. \& Pier, G. B. (1983). Pseudomonas aeruginosa isolates from patients with cystic fibrosis: a class of serum-sensitive, nontypable strains deficient in lipopolysaccharide $\mathrm{O}$ side chains. Infect Immun 42, 170-177.

Hodgins, G. R. (1961). Chelating agents. In Handbook of Chemistry and Physics, 43rd edn, pp. 1476-1491. Edited by C. D. Hodgman, R. C. Weast \& S. M. Selby. Cleveland, OH: The Chemical Rubber Publishing Company.

Höfte, M., Buysens, A., Koedam, N. \& Cornelis, P. (1993). Zinc affects siderophore-mediated high affinity iron uptake systems in the rhizosphere Pseudomonas aeruginosa 7NSK2. Biometals $\mathbf{6}$, 85-91.

Howe, T. R. \& Iglewski, B. H. (1984). Isolation and characterization of alkaline protease-deficient mutants of Pseudomonas aeruginosa in vitro and in a mouse eye model. Infect Immun 43, 1058-1063.

Iglewski, B. H., Rust, L. \& Bever, R. (1990). Molecular analysis of elastase. In Pseudomonas: Biotransformations, Pathogenesis, and Evolving Biotechnology, pp. 36-43. Edited by S. Silver, A. M. Chakrabarty, B. Iglewski \& S. Kaplan. Washington, DC: American Society for Microbiology.

Kadurugamuwa, J. L. \& Beveridge, T. J. (1997). Natural release of virulence factors in membrane vesicles by Pseudomonas aeruginosa and the effect of aminoglycoside antibiotics on their release. J Antimicrob Chemother 40, 615-621.

Kessler, E. \& Safrin, M. (1988). Synthesis, processing, and transport of Pseudomonas aeruginosa elastase. J Bacteriol 170, 5241-5247.

Kessler, E., Safrin, M., Abrams, W. R., Rosenbloom, J. \& Ohman, 
D. E. (1997). Inhibitors and specificity of Pseudomonas aeruginosa LasA. J Biol Chem 272, 9884-9889.

Kessler, E., Safrin, M., Gustin, J. K. \& Ohman, D. E. (1998). Elastase and the LasA protease of Pseudomonas aeruginosa are secreted with their propeptides. J Biol Chem 273, 30225-30231.

Krogfelt, K. A., Utley, M., Krivan, H. C., Laux, D. C. \& Cohen, P. S. (2000). Specific phospholipids enhance the activity of $\beta$-lactam antibiotics against Pseudomonas aeruginosa. J Antimicrob Chemother 46, 377-384.

Kronborg, G. (1995). Lipopolysaccharide (LPS), LPS immune complexes and cytokines as inducers of inflammation in patients with cystic fibrosis and chronic Pseudomonas aeruginosa lung infection. APMIS 103, 1-30.

Kronborg, G., Fomsgaard, A., Galanos, C., Freudenberg, M. A. \& Hoiby, N. (1992). Antibody response to lipid A, core, and O sugars of the Pseudomonas aeruginosa lipopolysaccharide in chronically infected cystic fibrosis patients. J Clin Microbiol 30, 1848-1855.

Liu, P. V., Matsumoto, H., Kusama, H. \& Bergan, T. (1983). Survey of heat-stable, major somatic antigens of Pseudomonas aeruginosa. Int J Syst Bacteriol 33, 256-264.

Luzar, M. A. \& Montie, T. C. (1985). Avirulence and altered physiological properties of cystic fibrosis strains of Pseudomonas aeruginosa. Infect Immun 50, 572-576.

Martinez, A., Ostrovsky, P. \& Nunn, D. N. (1998). Identification of an additional member of the secretin superfamily of proteins in Pseudomonas aeruginos a that is able to function in type II protein secretion. Mol Microbiol 28, 1235-1246.

May, T. B. \& Chakrabarty, A. M. (1994). Isolation and assay of Pseudomonas aeruginosa alginate. Methods Enzymol 235, 295298.

Nicas, T. I., Frank, D. W., Stenzel, P., Bradley, J. \& Iglewski, B. H. (1985). Role of exoenzyme $S$ in chronic Pseudomonas aeruginosa lung infections. Eur J Clin Microbiol Infect Dis 4, 175-179.

Ochsner, U. A. \& Reiser, J. (1995). Autoinducer mediated regulation of rhamnolipid biosurfactant synthesis in Pseudomonas aeruginosa. Proc Natl Acad Sci US A 92, 6424-6428.

Ojeniji, B. (1994). Polyagglutinable Pseudomonas aeruginosa from cystic fibrosis patients: a survey. APMIS 102 (Suppl. 46), 1-44.

Olson, J. C. \& Ohman, D. E. (1992). Efficient production and processing of elastase and LasA by Pseudomonas aeruginosa require zinc and calcium ions. J Bacteriol 174, 4140-4147.

O'Toole, G. A., Pratt, L. A., Watnick, P. I., Newman, D. K., Weaver, V. B. \& Kolter, R. (1999). Genetic approaches to study of biofilms. Methods Enzymol 130, 91-109.

Passador, L., Cook, J. M., Gambello, M. J., Rust, L. \& Iglewski, B. H. (1993). Expression of Pseudomonas aeruginosa virulence genes requires cell-to-cell communication. Science $\mathbf{2 6 0}$, 1127-1130.

Paya, M., Terencio, M. C., Ferrandiz, M. L. \& Alcaraz, M. J. (1996). Involvement of secretory phospholipase A2 activity in the zymosan rat air pouch model of inflammation. $\mathrm{Br} J$ Pharmacol 117, 1773-1779.

Pearson, J. P., Gray, K. M., Passador, L., Tucker, K. D., Eberhard, A., Iglewski, B. H. \& Greenberg, E. P. (1994). Structure of the autoinducer required for expression of Pseudomonas aeruginosa virulence genes. Proc Natl Acad Sci U S A 91, 197-201.

Pearson, J. P., Passador, L., Iglewski, B. H. \& Greenberg, E. P. (1995). A second $\mathrm{N}$-acylhomoserine lactone signal produced by Pseudomonas aeruginosa. Proc Natl Acad Sci USA 92, 14901494.

Pearson, J. P., Pesci, E. C. \& Iglewski, B. H. (1997). Roles of
Pseudomonas aeruginosa las and $r h l$ quorum-sensing systems in the control of elastase and rhamnolipid biosynthesis genes. J Bacteriol 179, 5756-5767.

Preston, M. J., Seed, P. C., Toder, D. S., Iglewski, B. H., Ohman, D. E., Gustin, J. K., Goldberg, J. B. \& Pier, G. B. (1997). Contribution of proteases and LasR to the virulence of Pseudomonas aeruginosa during corneal infections. Infect Immun $\mathbf{6 5}$, 3086-3090.

Rossbach, S., Wilson, T. L., Kukuk, M. L. \& Carty, H. A. (2000). Elevated zinc induces siderophore biosynthesis genes and a $z n t A$ like gene in Pseudomonas fluorescens. FEMS Microbiol Lett 191, 61-70.

Rust, L., Pesci, E. C. \& Iglewski, B. H. (1996). Analysis of the Pseudomonas aeruginosa elastase (lasB) regulatory region. J Bacteriol 178, 1134-1140.

Shortridge, V. D., Lazdunski, A. \& Vasil, M. L. (1992). Osmoprotectants and phosphate regulate expression of phospholipase $\mathrm{C}$ in Pseudomonas aeruginosa. Mol Microbiol 6, 863-871.

Speert, D. P., Dimmick, J. E., Pier, G. B., Saunders, J. M., Hancock, R. E. W. \& Kelly, N. (1987). An immunohistological evaluation of Pseudomonas aeruginosa pulmonary infection in two patients with cystic fibrosis. J Clin Microbiol 22, 743-747.

Suh, S., Silo-Suh, L., Woods, D., Hassett, D. J., West, S. \& Ohman, D. E. (1999). Effect of $r p o S$ mutation on the stress response and expression of virulence factors in Pseudomonas aeruginosa. J Bacteriol 181, 3890-3897.

Swift, S., Karlyshev, A. V., Fish, L., Durant, E. L., Winson, M. K., Chhabra, S. R., Williams, P., Maclntyre, S. \& Stewart, G. S. (1997). Quorum sensing in Aeromonas hydrophila and Aeromonas salmonicida: identification of the LuxRI homologs AhyRI and AsaRI and their cognate $\mathrm{N}$-acylhomoserine lactone signal molecules. J Bacteriol 179, 5271-5281.

Tang, H., Kays, M. \& Prince, A. (1995). Role of Pseudomonas aeruginosa pili in acute pulmonary infection. Infect Immun 63, 1278-1285.

Tang, H. B., DiMango, D., Bryan, R., Gambello, M., Iglewski, B. H., Goldberg, J. B. \& Prince, A. (1996). Contribution of specific Pseudomonas aeruginosa virulence factors to pathogenesis of pneumonia in a neonatal mouse model of infection. Infect Immun 64, 37-43.

Telford, G., Wheeler, D., Williams, P., Tomkins, P. T., Appleby, P., Sewell, H., Stewart, G. S. A. B., Bycroft, B. W. \& Pritchard, D. I. (1998). The Pseudomonas aeruginosa quorum-sensing signal molecule $\mathrm{N}$-(3-oxododecanoyl)-L-homoserine lactone has immunomodulatory activity. Infect Immun 66, 36-42.

Toder, D. S., Ferrell, S. J., Nezezon, J. L., Rust, L. \& Iglewski, B. H. (1994). las $A$ and lasB genes of Pseudomonas aeruginosa: analysis of transcription and gene product activity. Infect Immun 62, 1320-1327.

Tommassen, J., Fillous, A., Bally, M., Murgier, M. \& Lazdunski, A. (1992). Protein secretion in Pseudomonas aeruginosa. FEMS Microbiol Rev 9, 73-90.

Van Delden, C. \& Iglewski, B. (1998). Cell-to-cell signaling and Pseudomonas aeruginosa infections. Emerg Infect Dis 4, 551-560.

Vasil, M. L. \& Ochsner, U. A. (1999). The response of Pseudomonas aeruginosa to iron: genetics, biochemistry and virulence. Mol Microbiol 34, 399-413.

Vasil, M. L., Prince, R. W. \& Shortridge, V. D. (1993). Exoproducts : Pseudomonas exotoxin A and phospholipase C. In Pseudomonas aeruginosa the Opportunist: Pathogenesis and Disease, pp. 59-77. Edited by R. B. Fick, Jr. Boca Raton, FL: CRC Press.

Whiteley, M., Lee, K. M. \& Greenberg, E. P. (1999). Identification 
of genes controlled by quorum sensing in Pseudomonas aeruginosa. Proc Natl Acad Sci US A 96, 13904-13909.

Whiteley, M., Parsek, M. R. \& Greenberg, E. P. (2000). Regulation of quorum sensing by RpoS in Pseudomonas aeruginosa. J Bacteriol 182, 4356-4360.

Winson, M., Camara, M., Latifi, A. \& 10 other authors (1995). Multiple $\mathrm{N}$-acyl-L-homoserine lactone signal molecules regulate production of virulence determinants and secondary metabolites in Pseudomonas aeruginosa. Proc Natl Acad Sci USA 92, 9427-9431.

Woods, D. E., Cryz, S. J., Friedman, R. L. \& Iglewski, B. H. (1982).
Contribution of extoxin A and elastase to virulence of Pseudomonas aeruginosa in chronic lung infections of rats. Infect Immun 36, 1223-1228.

Zhou, X., George, S. E., Frank, D. W., Utley, M., Gilmour, I., Krogfelt, K. A., Claxton, L. D., Laux, D. C. \& Cohen, P. S. (1997). Isolation and characterization of an attenuated strain of Pseudomonas aeruginosa, a 3,5-dichlorobenzoate degrader. Appl Environ Microbiol 63, 1389-1395.

Received 10 December 2001; revised 14 February 2002; accepted 15 February 2002. 